Ulrich Horst

Bischöfe und Ordensleute 



\section{Ulrich Horst}

\section{Bischöfe}

\section{und \\ Ordensleute}

Cura principalis animarum und via perfectionis in der Ekklesiologie des hl. Thomas von Aquin

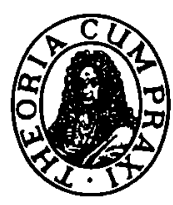

Akademie Verlag 
Die Deutsche Bibliothek - CIP-Einheitsaufnahme

\section{Horst, Ulrich:}

Bischöfe und Ordensleute : Cura principalis animarum und via perfectionis in der Ekklesiologie

des hl. Thomas von Aquin / Ulrich Horst. -

Berlin : Akad. Verl. 1999

ISBN 3-05-003416-5

(C) Akademie Verlag GmbH, Berlin 1999

Gedruckt auf chlorfrei gebleichtem Papier.

Das eingesetzte Papier ist alterungsbeständig nach DIN/ISO 9706.

Alle Rechte, insbesondere die der Übersetzung in andere Sprachen, vorbehalten. Kein Teil dieses Buches darf ohne schriftliche Genehmigung des Verlages in irgendeiner Form - durch Photokopie, Mikroverfilmung oder irgendein anderes Verfahren - reproduziert oder in eine von Maschinen, insbesondere von Datenverarbeitungsmaschinen, verwendbare Sprache übertragen oder übersetzt werden.

Druck: GAM Media, Berlin

Bindung: Druckhaus „Thomas Müntzer“, Bad Langensalza

Printed in the Federal Republic of Germany 